\title{
Synthesis and characterization of polymer (sulfonated poly-ether-ether-ketone) based nanocomposite (h-boron nitride) membrane for hydrogen storage
}

\author{
R. Naresh Muthy ${ }_{1}^{a, *}$, S. Rajashabala ${ }^{a, b},{ }_{1}^{R}$. Kannan ${ }^{c}$ \\ a School of Physics, Madurai Kamaraj University, Madurai 625021, Tamil Nadu, India \\ ${ }^{b}$ Department of Chemistry and Biochemistry, Utah State University, Logan, UT 84322-0300, USA \\ ${ }^{\mathrm{c}}$ Department of Physics, University College of Engineering, Anna University, Dindigul 624622, Tamil Nadu, India
}

\section{A R T I CLE IN F O}

\section{Article history:}

Received 7 August 2014

Received in revised form

20 November 2014

Accepted 27 November 2014

Available online $\mathrm{xxx}$

\section{Keywords:}

Polymer nanocomposite (SPEEK-h-

\section{BN) membrane}

Phase inversion technique

Seivert's hydrogenation setup

Hydrogen storage

\begin{abstract}
A B S T R A C T
The development of light weight and compact hydrogen storage materials is still prerequisite to fuel-cell technology to be fully competitive. The present experimental study reports the hydrogen storage capability of sulfonated poly-ether-ether-ketone (SPEEK)-hexagonal boron nitride ( $\mathrm{h}-\mathrm{BN}$ ) (SPEEK-h-BN) nanocomposite membranes. The nanocomposite membranes are prepared by considering various amount of $\mathrm{h}-\mathrm{BN}(0,1,3$ and $5 \mathrm{wt} \%$ ) by phase inversion technique. The degree of sulfonation of the PEEK (SPEEK) is found to be $65 \%$ by Proton Nuclear Magnetic Resonance ( ${ }^{1} \mathrm{H}$ NMR) spectroscopy. Hydrogen adsorption studies have been carried out using a Seiverts-like hydrogenation setup. The membranes are characterized by X-ray Diffractometer (XRD), Micro-Raman spectroscopy, Fourier Transform Infrared (FTIR) spectroscopy, Scanning Electron Microscopy (SEM), Atomic Force Microscopy (AFM), CHN-elemental analysis and Thermo Gravimetric Analysis (TGA). It is observed that the SPEEK- $5 \%$ h-BN membrane performs better than pure SPEEK membrane, has maximum storage capacity of $2.98 \mathrm{wt} \%$ at $150^{\circ} \mathrm{C}$ and the adsorbed hydrogen has an average binding energy of $0.38 \mathrm{eV}$. The TGA study shows the dehydrogenation behavior of hydrogenated SPEEK-h-BN nanocomposite membrane and it is found to be in the temperature range of 214 $-218^{\circ} \mathrm{C}$ for SPEEK- $5 \%$ h-BN membrane.

Copyright $₫ 2014$, Hydrogen Energy Publications, LLC. Published by Elsevier Ltd. All rights
\end{abstract}

reserved.

\section{Introduction}

The major challenges in the recent years are the reduction of fossil fuels and global warming [1]. Necessity is the driving force for finding innovative technologies. Alternative energy sources like wind, solar, super capacitor and fuel cells have been developed recently and are used effectively. Nowadays hydrogen is considered as the most promising and potential altemative energy carrier that can facilitate the transition from fossil fuels to sources of clean energy $[2,3]$. The development of fuel cell power systems has enabled hydrogen as an

* Corresponding author. Tel: +91 7708980409(mobile).

E-mail address: rnaresh7708@gmail.com (R. Naresh Muthu). http://dx.doi.org/10.1016/j.ijhydene. 2014.11.136

0360-3199/Copyright $\bigcirc 2014$, Hydrogen Energy Publications, LLC. Published by Elsevier Ltd. All rights reserved. 
alternative to conventional systems [4]. Although hydrogen is often presented as the fuel of the future, the development of a hydrogen-based fuel is rather difficult Hydrogen has to be produced, stored, distributed and used, but each of these steps is hindered due to several factors [5]. Multiple challenges must be overcome to achieve the vision of secure, abundant, inexpensive, and clean hydrogen production with low carbon emissions $[4,6,7]$.

In the prospect of a hydrogen-based economy, the major issue is to address how to reversibly store hydrogen while minimizing energy consumption. Three major approaches $[8,9]$, compression for storage in tank, storage by purely physical absorption and storage via chemical reaction or chemical storage are in the forefront of current research efforts. Direct use of compressed hydrogen as a fuel encounters major constraints due to large tank volumes, short lifetimes of the storage system and stringent safety measures, in addition to high investment costs and portability.

A lot of research works have been carried out on hydrogen rich materials like chemical hydrides [10], complex hydrides [11] and metal hydrides [12] that store hydrogen by chemisorption. In the last two decades, over 350 distinct materials have been investigated experimentally [13] and more than $70 \%$ have been discontinued as potential candidates for hydrogenfuel cells. Although some complex metal hydrides (such as, $\mathrm{MgH}_{2}, \mathrm{NaBH}_{4}, \mathrm{Ca}\left(\mathrm{BH}_{3}\right)_{2}, \mathrm{AlH}_{3}, \mathrm{~K}_{2} \mathrm{LiAlH}_{6}$, etc.) have advantages of high gravimetric density $\left(\sim 15-20\right.$ wt. $\%$ of $\left.\mathrm{H}_{2}\right)$ and high volumetric density (about $150 \mathrm{~g} \mathrm{H}_{2} / \mathrm{L}$ ), major disadvantages were found to be high desorption energy, slow kinetics and toxic byproducts, besides cyclability as a major issue.

Large specific surface area materials such as carbon nanotubes [14], metalorganic frameworks [15,16] and zeolites $[15,17]$ store hydrogen by physisorption and in most of these cases hydrogen uptake are not so high. Recent reports have demonstrated that boron nitride $(\mathrm{BN})$ nanomaterial can be used as a potential hydrogen storage medium [18-22]. Hexagonal boron nitride ( $\mathrm{h}-\mathrm{BN}$ ) is an analog of graphite, has unique physical and chemical properties, including high specific surface area, low density, high mechanical strength and oxidation resistance [22-24]. Weng et al. [18] reported the ability of BN porous microbelts to exhibit high and reversible hydrogen uptake of $2.3 \mathrm{wt}$. \% at $77 \mathrm{~K}$ and $1 \mathrm{MPa}$. Wang et al. [19] reported a hydrogen storage capacity of $2.6 \mathrm{wt} \%$ in h-BN powders under the hydrogen pressure of $1.0 \mathrm{MPa}$. The conventional BN nanopowder, multiwalled BNNT and bamboolike BNNTs can absorb hydrogen up to $0.2,1.8$ and 2.6 wt. \%, respectively at room temperature and at $10 \mathrm{MPa}$ [20]. The hydrogen storage capacity of $4.2 \mathrm{wt}$. $\%$ at $10 \mathrm{MPa}$ in BNNTs collapsed walls [21] and $5.6 \mathrm{wt}$. $\%$ at $3 \mathrm{MPa}$ at room temperature in $\mathrm{BN}$ porous whiskers were noticed [22].

The other promising route is the use of polymers/polymer nanocomposites that have also been considered for hydrogen storage $[4,6,25-35]$. Keown et al. [25] found that polymer of intrinsic microporosity (PIMs) stores $1.7 \mathrm{wt}$. \% of hydrogen at $77 \mathrm{~K}$ and $10 \mathrm{bar}$. The hypercrosslinked polystyrene could store $2.75 \mathrm{wt}$. \% of hydrogen at $77 \mathrm{~K}$ and 10 bar [26]. The hydrogen storage capacity of $\mathrm{HCl}$ treated conducting polymers like polyaniline (PANI) and polypirrole (Ppy) were found to be 6 and 8 wt. \%, respectively at room temperature and at $9.3 \mathrm{MPa}$ [27]. The hydrogen storage ability of the hypercrosslinked polymers with platinum $(\mathrm{Pt})$ nanoparticles was analyzed and a maximum storage capacity of 0.21 wt. $\%$ at $298.15 \mathrm{~K}$ and 19 bar was noticed [28]. Hypercrosslinked polystyrene - Pt nanoparticles display a hydrogen uptake of $0.36 \mathrm{wt}$. \% at $294 \mathrm{~K}$ and $100 \mathrm{~atm}$ [29]. The PANI impregnated with tin oxide, multiwall carbon nanotubes (MWCNTs) and aluminum powder (Al) exhibit $0.31,0.38,0.5 \mathrm{wt}$. $\%$ of hydrogen adsorption at $115^{\circ} \mathrm{C}$ and 70 bar [30]. Hydrogen storage capacity of halloysite nanotubes (HNT) - PANI nanocomposite was examined by Attia et al. [31] and noticed $0.78 \mathrm{wt} \%$ of hydrogen was stored at room temperature and a pressure of $0.5 \mathrm{MPa}$. The hydrogen storage capacity of poly (ether-ether-ketone) functionalized in situ by manganese oxide formation, showed a hydrogen storage capacity of $1.2 \mathrm{wt}$. \% at $77 \mathrm{~K}[6]$. The hydrogen storage capacity of acid treated water-soluble polymers such as polyvinyl alcohol (PVA) and polyvinyl pyrrolidone (PVP) doped single-walled carbon nanotubes (SWCNTs) has shown to be 1.2 and 1.5 wt. $\%$, respectively at $50^{\circ} \mathrm{C}$ [32]. Kim et el [33]. reported that the PANI - vanadium oxide nanocomposites (VONC) showed storage capacity of $1.8 \mathrm{wt}$. \% at $77 \mathrm{~K}$ and $70 \mathrm{bar}$. The activated rectangular PANI-based carbon tubes (ARP-CTs) exhibited the hydrogen adsorption of $5.2 \mathrm{wt} . \%$ at $77 \mathrm{~K}$ and $5 \mathrm{MPa}$ and $0.62 \mathrm{wt}$. \% at $293 \mathrm{~K}$ and $7.5 \mathrm{MPa}$ respectively [34]. Makridis et al. [4] studied $\mathrm{Mg}$ doped polymethylmethacrylate (PMMA) which exhibited 6 wt. $\%$ at $250^{\circ} \mathrm{C}$. The Li-conjugated microporous polymers could able to store more than 6 wt \% of hydrogen at $77.3 \mathrm{~K}$ and at $1 \mathrm{bar}[35]$.

Up to date, none of the proposed hydrogen storage systems appears able to match US-DOE targets. Recent studies showed that the polymer nanocomposites could be an attractive material for hydrogen storage. The present work is aimed at the synthesis and characterization of light weight and compact hydrogen storage material based on polymer nanocomposite using sulfonated poly (ether-ether-ketone) (SPEEK) and hexagonal boron nitride ( $\mathrm{h}-\mathrm{BN}$ ) nanoparticles, where the PEEK has excellent mechanical and chemical properties and thermal stability $[36,37]$. The dipolar nature of $\mathrm{B}-\mathrm{N}$ bonds in hexagonal boron nitride $(\mathrm{h}-\mathrm{BN})$ can have stronger absorption of hydrogen from hydrocarbons. where phase inversion technique is employed for the preparation of microporous SPEEK-h-BN nanocomposite membranes. So it is expected that the light weight and more microporous nature of SPEEK could accommodate more h-BN nanoparticles which in tum can adsorb more hydrogen molecules.

\section{Experimental methods}

\section{Materials}

The PEEK polymer from Sigma Aldrich and h-BN (99.99\% punity) with average particle size of $70 \mathrm{~nm}$ from Sisco Research Laboratories were purchased. Concentrated sulfuric acid $\left(\mathrm{H}_{2} \mathrm{SO}_{4}\right)$ (98\%) and $\mathrm{N}, \mathrm{N}$-Dimethylformamide (DMF) were received from Merck.

\section{Preparation of SPEEK}

The present work involves preparation of sulfonated PEEK and SPEEK-h-BN nanocomposite membranes for the hydrogen 


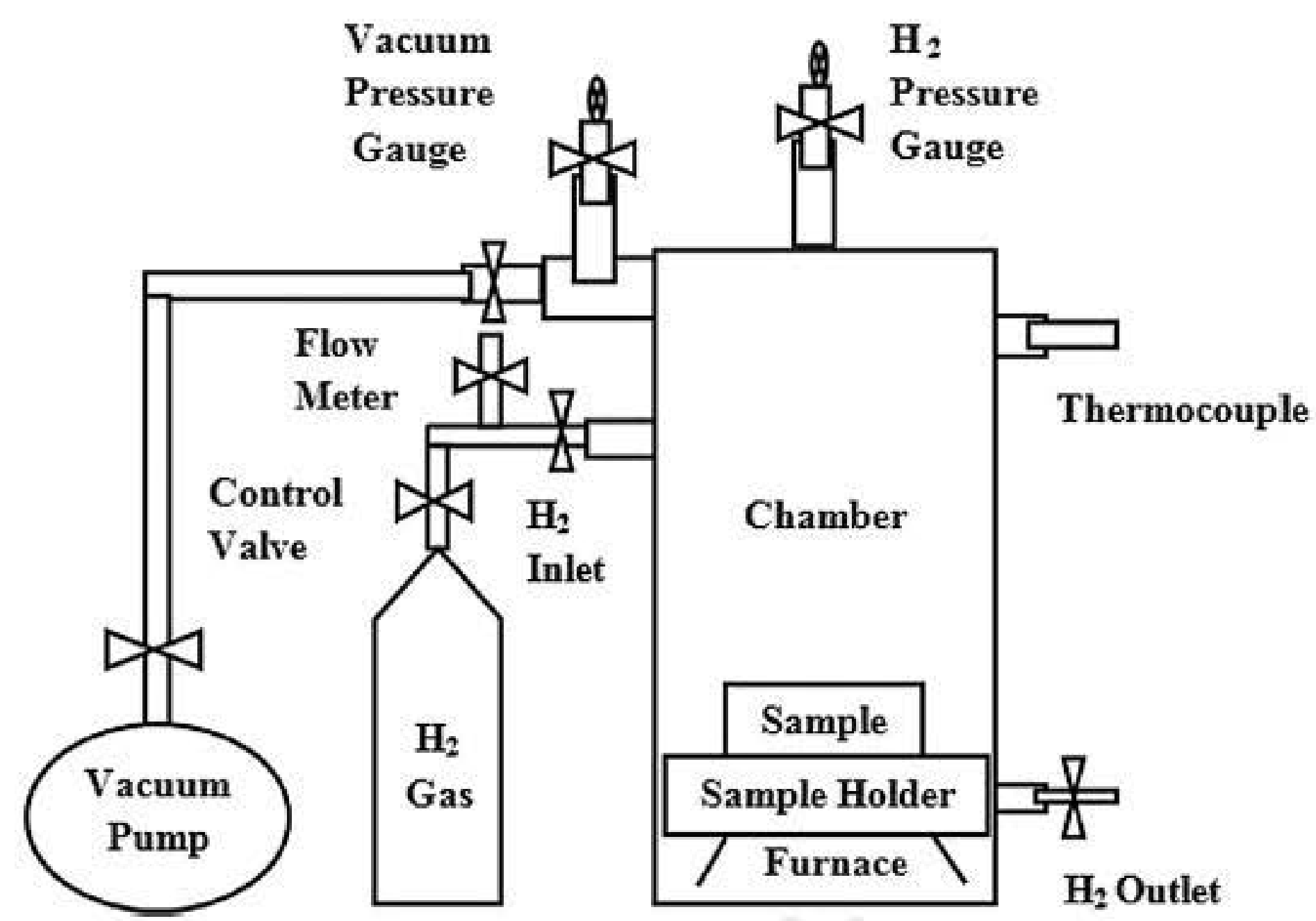

Fig. 1 - Schematic diagram of Sieverts-like hydrogenation setup.

adsorption studies. Poly (ether-ether ketone) (PEEK) was sulfonated as described in literature $[36,38,39]$. The pure PEEK polymer was dried in a vacuum oven at $100^{\circ} \mathrm{C}$ for $12 \mathrm{~h}$, then dissolved in concentrated sulfuric acid $(98 \%)$ and heated to $40^{\circ} \mathrm{C}$ under constant stirning for $24 \mathrm{~h}$. This solution was decanted into large excess of ice-cold water to precipitate the acid polymer. The precipitate obtained was repeatedly washed with distilled water until the rinsed water has a $\mathrm{pH}$ value above 6 . The washed precipitate was further dried at $100^{\circ} \mathrm{C}$ for $12 \mathrm{~h}$. The final product obtained was sulfonated PEEK, which has the desired degree of sulfonation.

\section{Preparation of SPEEK-h-BN nanocomposite membranes}

The SPEEK-h-BN nanocomposite membranes were prepared with $0,1,3$ and $5 \mathrm{wt} \%$ of $\mathrm{h}$ - $\mathrm{BN}$ using a phase inversion technique $[38,40,41]$. To fabricate SPEEK-h-BN nanocomposite membranes, SPEEK polymer was dissolved in N, N-Dimethylformamide and water (non-solvent). Then h-BN nanoparticles were taken with $\mathrm{N}, \mathrm{N}$-Dimethylformamide at $100 \mathrm{mg} /$ $5 \mathrm{ml}$ concentration. To allow h-BN nanoparticles to be dispersed uniformly the mixture was kept in an ultrasonic bath at room temperature for $1 \mathrm{~h}$. Then both the solutions were magnetic stirred. After getting homogeneous solution it was casted on a glass plate. Then it was heated at $60^{\circ} \mathrm{C}$ for $5 \mathrm{~h}$ and dried at $100{ }^{\circ} \mathrm{C}$ for $20 \mathrm{~h}$ in vacuum in order to avoid moisture. The thickness of the resulting membranes was found to be in the range of $52 \pm 10 \mu \mathrm{m}$.

\section{Hydrogenation studies}

Hydrogen adsorption studies have been carried out for the developed SPEEK-h-BN nanocomposite membranes using Sievert's-like hydrogenation setup and its schematic diagram is shown in Fig. 1. The details of hydrogenation procedure are as follows. Before hydrogenation, the chamber should be free from leak. The prepared membranes were loaded in the sample container and the hydrogen was flushed few times within the chamber for proper flow. The membranes were maintained in a vacuum at $150^{\circ} \mathrm{C}$ for $1 \mathrm{~h}$. Then the hydrogen was allowed to react with these membranes at a constant flow rate of $\chi^{0.5} \mathrm{~L} / \mathrm{min}$ for $15 \mathrm{~min}$, where the equilibrium pressure of the chamber was maintained at $1 \mathrm{~kg} / \mathrm{cm}^{2}$. The hydrogenated membranes were kept in the chamber to attain room temperature.

\section{Characterization}

Powder X-ray diffraction (XRD) technique (X'Pert PAN analytical diffractometer), Micro-Raman spectroscopy (Labram HR800), Fourier Transform Infrared (FTIR) spectroscopy (FTIR8400 , CE, Shimadzu model), Scanning Electron Microscopy (SEM, JEOL-MODEL 6390), Atomic force microscopy (AFM, A100 SGS), CHN - elemental analysis (Elementar Vario EL III), Thermo Gravimetric Analysis (TGA, SII EXSTAR 6000), Proton Nuclear Magnetic Resonance ( ${ }^{1} \mathrm{H}$ NMR) spectroscopy (Bruker $300 \mathrm{MHz}$ ) were used to examine the structure, composition, functional groups, desorption temperature and degree of sulfonation of the prepared nanocomposite membranes.

\section{Results and discussion}

The Degree of Sulfonation (DS) is estimated from ${ }^{1} \mathrm{H}$ NMR spectrum by finding the ratio of peak area of the distinct $\mathrm{H}_{\mathrm{E}}$ signal $\left(\mathrm{A}_{\mathrm{H}}\right)$ to the peak area of all the other aromatic hydrogens $\left(\mathrm{A}_{\mathrm{H}_{\mathrm{A} i \mathrm{BSB}} \mathrm{CD}}\right)$. The aromatic hydrogens are denoted by the symbol " $\mathrm{H}_{\mathrm{x}}$ " in the SPEEK structure, where $\mathrm{x}=\mathrm{A}, \mathrm{A}, \mathrm{B}, \mathrm{B}$ 'C, D [38]. Scheme 1 shows the presence of various aromatic protons in the SPEEK structure [37,38]. 
<smiles>COc1ccc(Oc2ccc(C(=O)c3ccc(F)cc3)cc2)c(S(=O)(=O)O)c1</smiles>

Scheme 1 - Structure of SPEEK.

Fig. 2 displays the ${ }^{1} \mathrm{H}$ NMR spectrum of SPEEK and has a distinct signal at $7.5 \mathrm{ppm}$ that indicates the presence of protons of the $-\mathrm{SO}_{3} \mathrm{H}$ group. DS can be calculated from the following formula $[36,37,39]$.

$\frac{\mathrm{n}}{12-2 \mathrm{n}}=\frac{\mathrm{A}_{\mathrm{H}_{\mathrm{E}}}}{\sum \mathrm{A}_{\mathrm{H}_{\mathrm{A}}, \mathrm{s} ; \mathrm{i}, \mathrm{CD}}}$

Q2 where ' $n$ ' is the number of $H_{E}$ per repeat unit

$\mathrm{DS}(\%)=\mathrm{n} \times 100$

The estimated degree of sulfonation of our prepared SPEEK is $65 \%$. In general, the DS of $40-70 \%$ produces a more mechanically and thermally stable polymer of SPEEK $[39,42]$.

Fig. 3 shows the XRD patterns of SPEEK-0\%h-BN, SPEEK- $1 \%$ h-BN, SPEEK- $3 \%$ h-BN and SPEEK- $5 \%$ h-BN nanocomposite membranes. Fig. 3(a) shows a very broad peak centered at $22^{\circ}$, which indicates the amorphous nature [43] of SPEEK membrane. A characteristic sharp reflection at $2 \theta=27^{\circ}$ in Fig. 3(b-d) confirms the presence of h-BN in the prepared nanocomposite membranes [44]. It is noticed that the intensity of h-BN peak increases with increase of h-BN content in the nanocomposite membranes and it is the clear evidence for the crystalline nature of nanocomposite membranes $[45,46]$. The absence of any other peak except SPEEK and h-BN proves that the prepared nanocomposite membranes are free from impurities.

Fig. 4 shows the Raman spectra of SPEEK- $0 \%$ h-BN, SPEEK$1 \% \mathrm{~h}-\mathrm{BN}, \mathrm{SPEEK}-3 \% \mathrm{~h}-\mathrm{BN}$ and SPEEK- $\%$ h-BN nanocomposite membranes. Fig. 4(a) indicates a Raman mode for SPEEK polymer at $1149 \mathrm{~cm}^{-1}$ and is attributed to the sulfonation [47]. In Fig. 4(b-d), the sharp peak of $\mathrm{E}_{2 \mathrm{~g}}$ mode appears at $1367 \mathrm{~cm}^{-1}$ corresponding to the $\mathrm{h}-\mathrm{BN}$ and is due to the in-plane atomic displacement of $\mathrm{B}$ and $\mathrm{N}$ atoms against each other [48]. The intensity of the h-BN mode $\left(1367 \mathrm{~cm}^{-1}\right)$ increases compared to SPEEK mode $\left(1149 \mathrm{~cm}^{-1}\right)$ as the content of $\mathrm{h}-\mathrm{BN}$ nanoparticles increases in SPEEK and enhances the crystalline nature of the nanocomposite membranes and it is confirmed by XRD results.

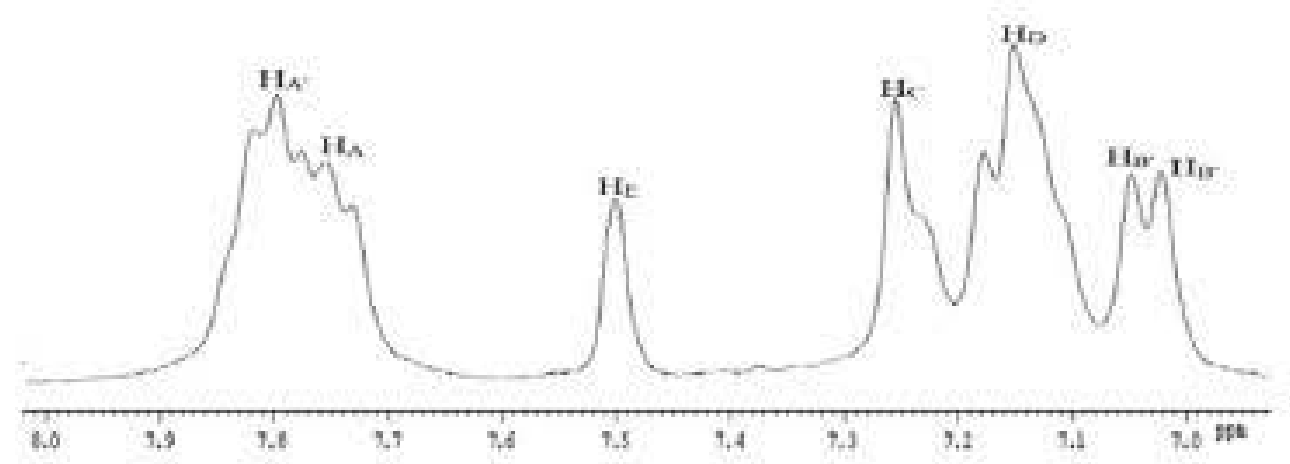

Fig. 2 - ${ }^{1} \mathrm{H}$ NMR spectrum of Sulfonated PEEK in DMSO-d .

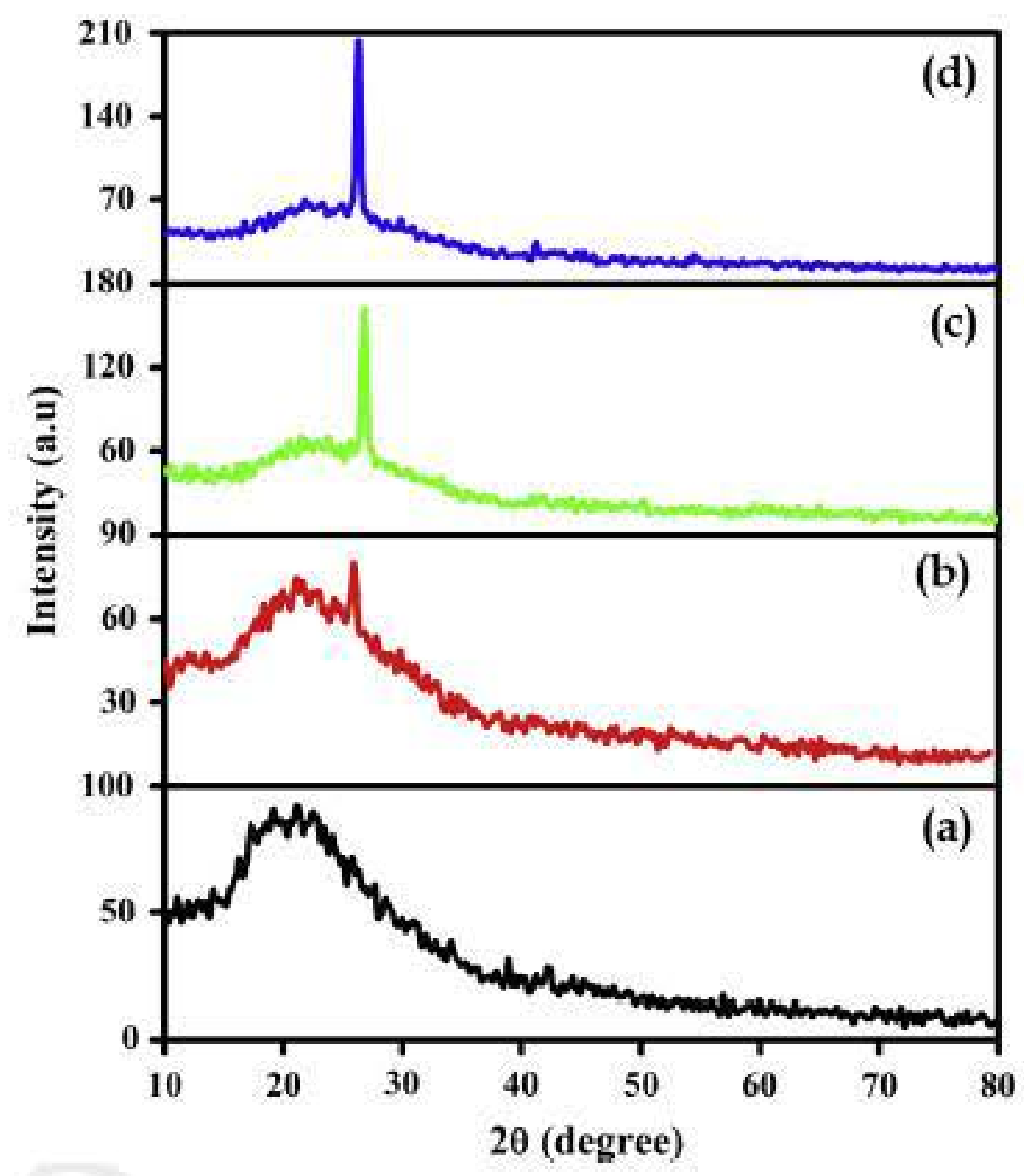

Fig. 3 - XRD profile of (a) SPE्तK- $0 \%$ h-BN (b) SPEEK-1\%h-BN (c) SPEEK-3\%h-BN and (d) SPEEK-5\%h-BN nanocomposite membranes.

The presence of functional groups has been determined from the bands appearing in the FTIR spectrum and Fig. 5 shows the FTIR spectra of SPEEK and SPEEK-h-BN nanocomposites. The IR spectrum of SPEEK (Fig. 5(a)) has the

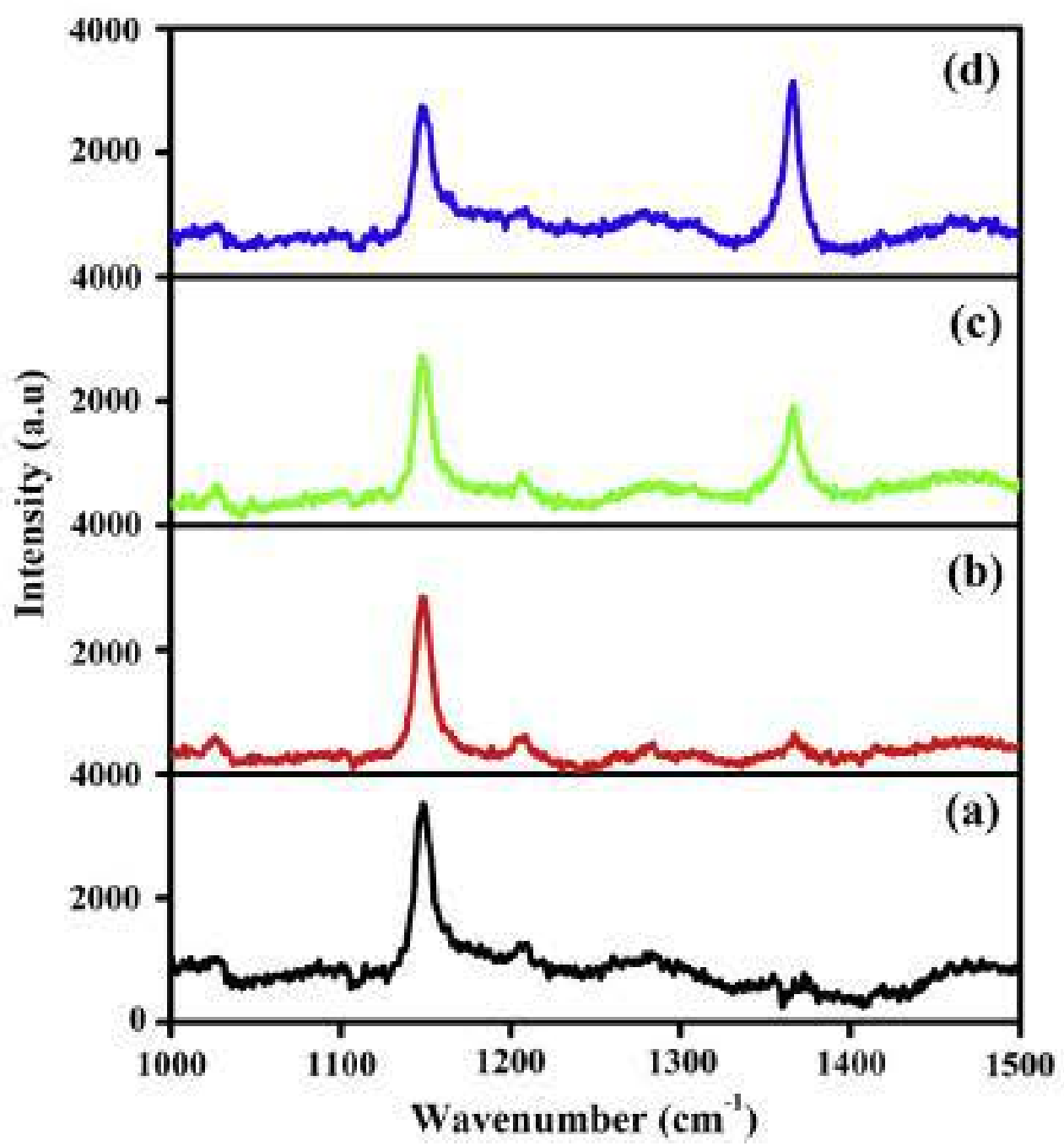

Fig. 4 - Raman spectra of (a) SPE्रK-0\%h-BN (b) SPEEK-1\%hBN (c) SPEEK-3\%h-BN and (d) SPEEK-5\%h-BN nanocomposite membranes. 


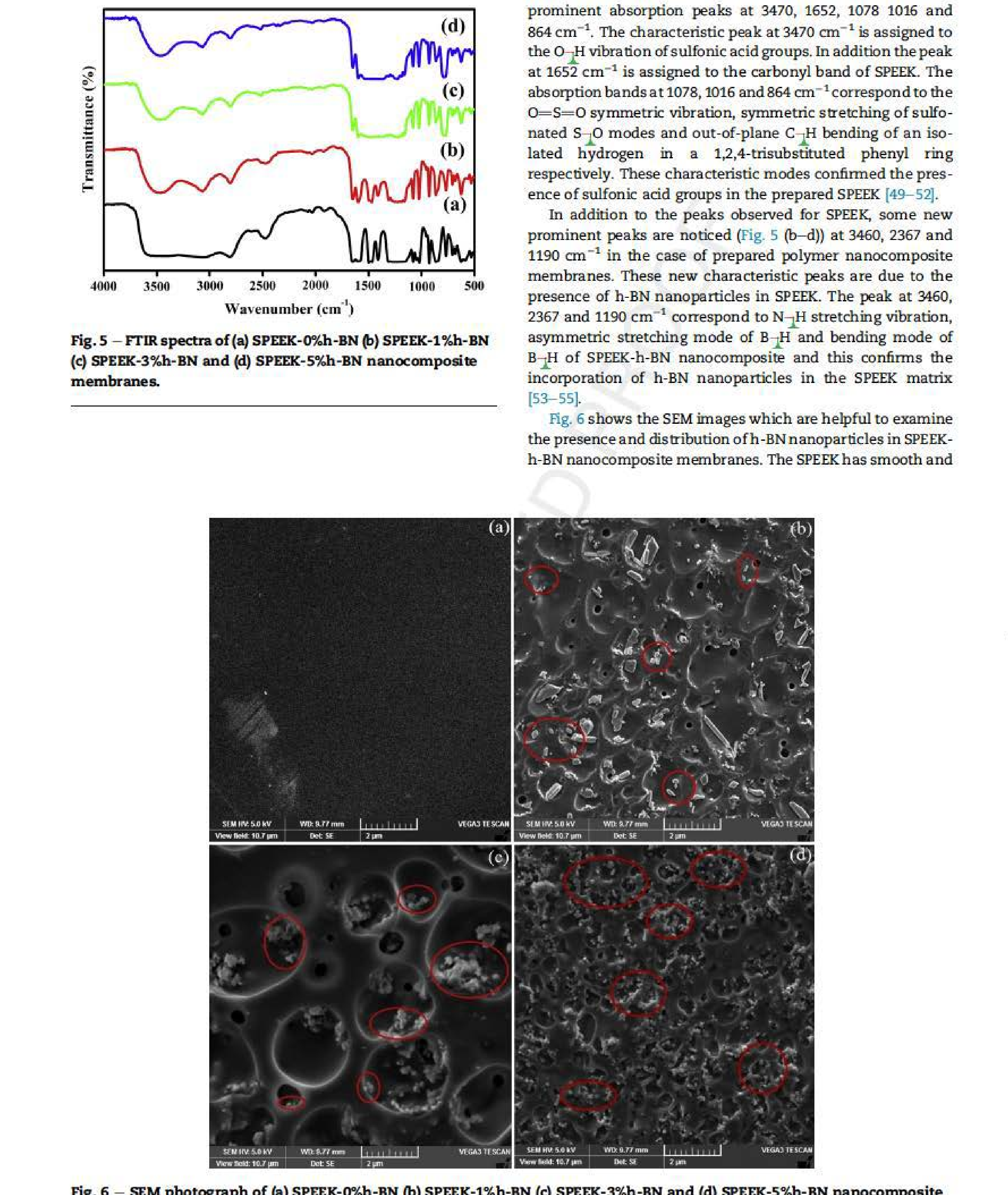

Fig. 5 - FTIR spectra of (a) SPEEK-0\%h-BN (b) SPEEK-1\%h-BN (c) SPEEK-3\%h-BN and (d) SPEEK-5\%h-BN nanocomposite membranes.
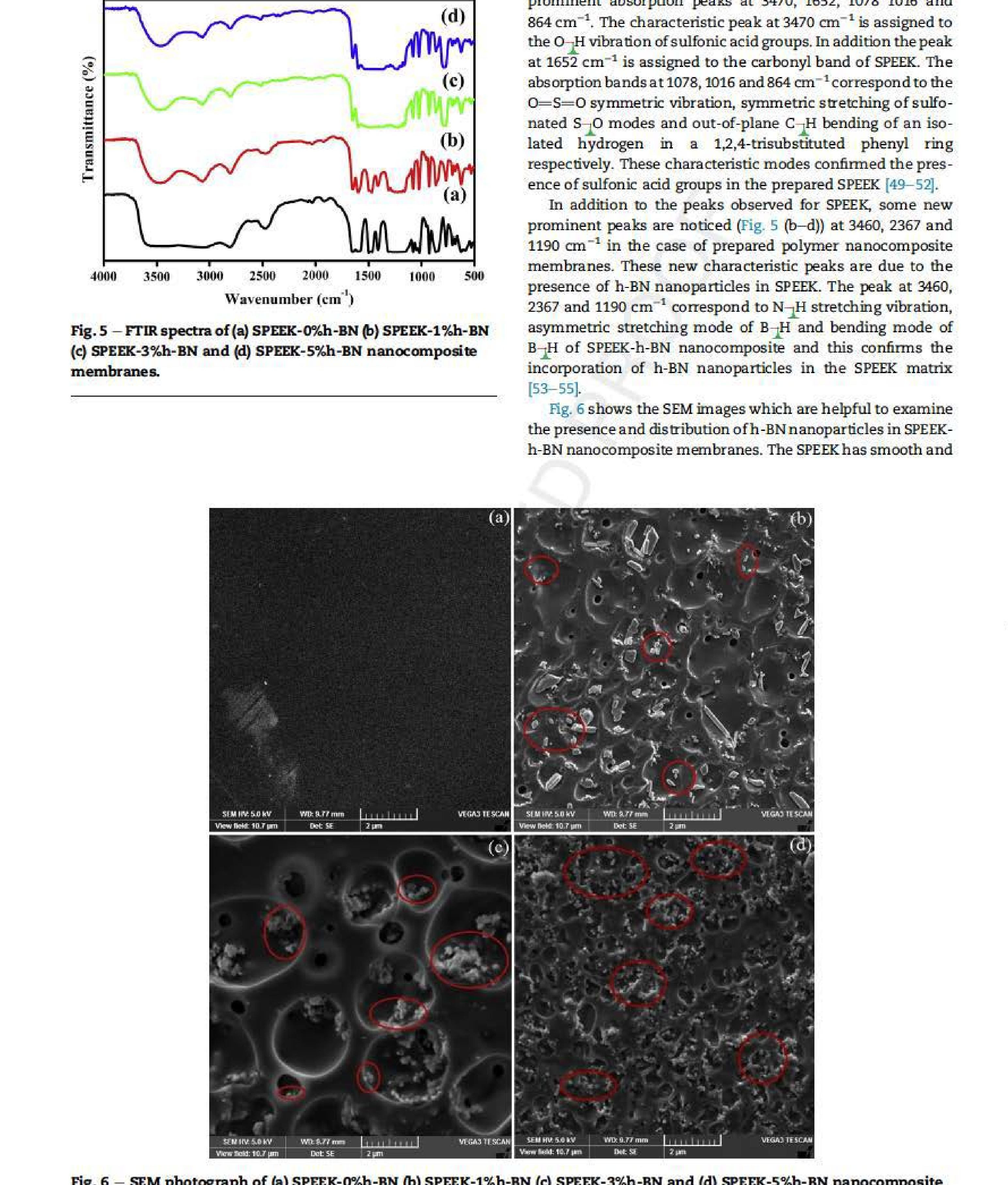

Fig. 6 - SEM photograph of (a) SPEEK-0\%h-BN (b) SPEEK-1\%h-BN (c) SPEEK-3\%h-BN and (d) SPEEK-5\%h-BN nanocomposite membranes.

Please cite this article in press as: Naresh Muthu R, et al., Synthesis and characterization of polymer (sulfonated poly-etherether-ketone) based nanocomposite (h-boron nitride) membrane for hydrogen storage, International Joumal of Hydrogen Energy (2014), http://dx.doi.org/10.1016/j.jjhydene.2014.11.136

prominent absorption peaks at 3470, 1652, 10781016 and $864 \mathrm{~cm}^{-1}$. The characteristic peak at $3470 \mathrm{~cm}^{-1}$ is assigned to the $\mathrm{O}-\mathrm{H}$ vibration of sulfonic acid groups. In addition the peak at $1652 \mathrm{~cm}^{-1}$ is assigned to the carbonyl band of SPEEK. The absorption bands at 1078,1016 and $864 \mathrm{~cm}^{-1}$ correspond to the $\mathrm{O}=\mathrm{S}=\mathrm{O}$ symmetric vibration, symmetric stretching of sulfonated $\mathrm{S}_{1} \mathrm{O}$ modes and out-of-plane $\mathrm{C}_{{ }_{1}} \mathrm{H}$ bending of an isolated hydrogen in a 1,2,4-trisubstituted phenyl ring respectively. These characteristic modes confirmed the presence of sulfonic acid groups in the prepared SPEEK [49-52].

In addition to the peaks observed for SPEEK, some new prominent peaks are noticed (Fig. 5 (b-d)) at 3460, 2367 and $1190 \mathrm{~cm}^{-1}$ in the case of prepared polymer nanocomposite membranes. These new characteristic peaks are due to the presence of h-BN nanoparticles in SPEEK. The peak at 3460 , 2367 and $1190 \mathrm{~cm}^{-1}$ correspond to $\mathrm{N}_{-} \mathrm{H}$ stretching vibration, asymmetric stretching mode of $\mathrm{B}_{-} \mathrm{H}$ and bending mode of ${ }_{B}{ }_{2} \mathrm{H}$ of SPEEK-h-BN nanocomposite and this confirms the incorporation of $\mathrm{h}-\mathrm{BN}$ nanoparticles in the SPEEK matrix [53-55].

Fig. 6 shows the SEM images which are helpful to examine the presence and distribution of h-BN nanoparticles in SPEEKh-BN nanocomposite membranes. The SPEEK has smooth and
66

67

68

69

70

71

72

73

74

75

76

77

78

79

80

81

82

83

84

85

86 

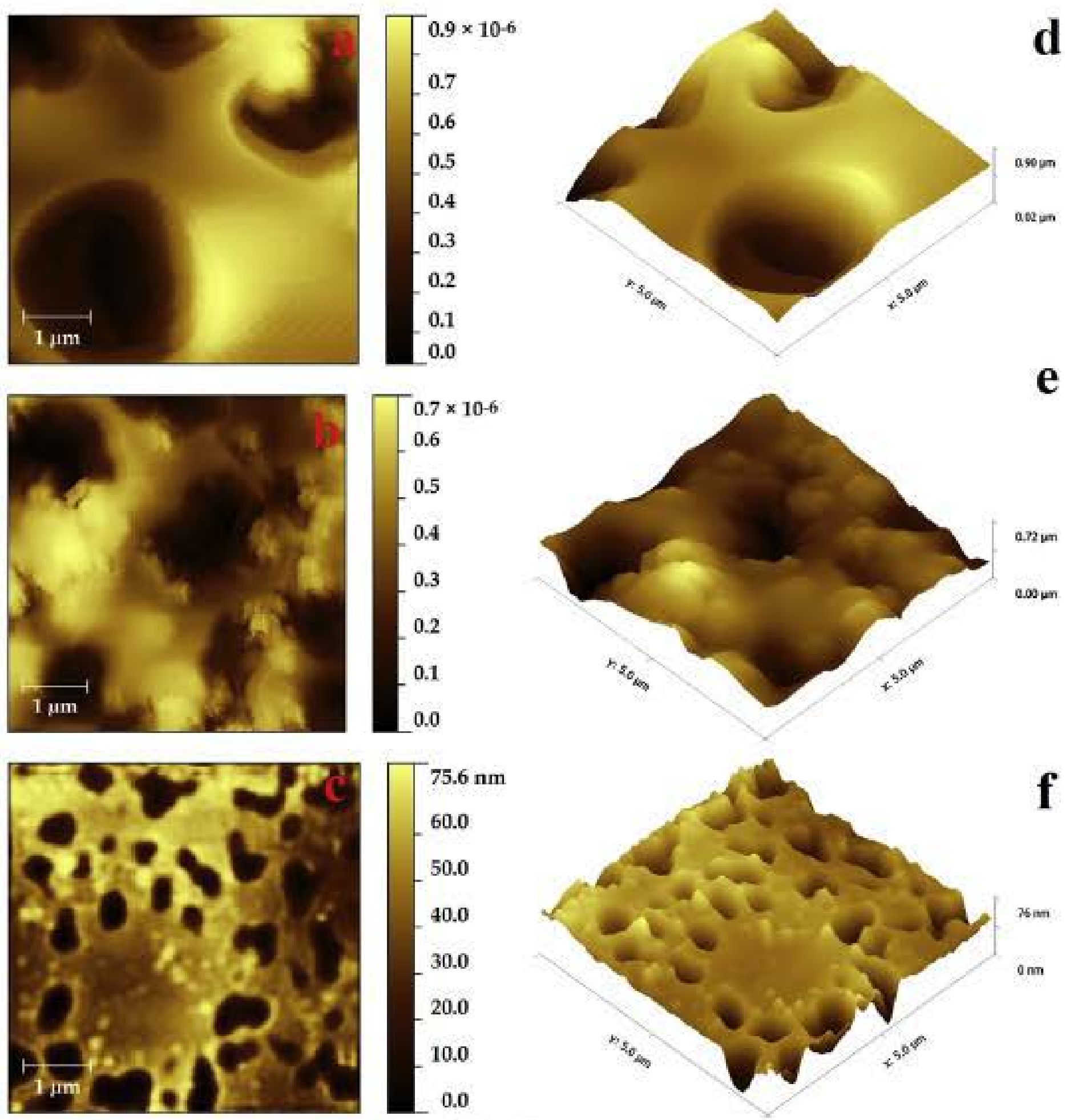

Fig. 7 - AFM images of (a) SPEEK-1\%h-BN (b) SPEEK-3\%h-BN (c) SPEEK-5\%h-BN nanocomposite membranes (Two dimensions) (d) SPEEK-1\%h-BN (e) SPEEK-3\%h-BN (f) SPEEK-5\%h-BN nanocomposite membranes (Three Dimensions).

uniform surface morphology (see Fig. 6a). This smooth morphology confirms the amorphous nature of SPEEK polymer which agrees well with our XRD results. The remaining micrograph depicts the porous structure, indicating the

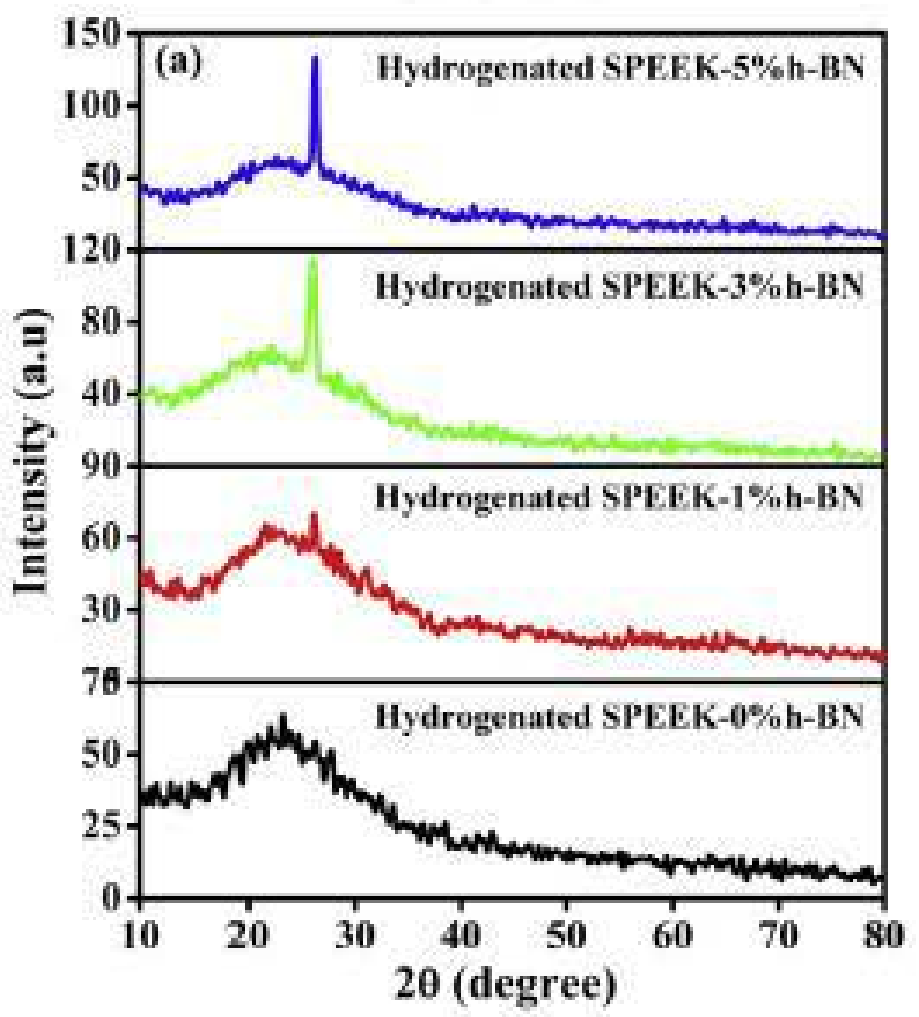

distribution of h-BN nanoparticles with the particle size in the range of $70,90 \mathrm{~nm}$ and some of h-BN nanoparticles agglomerated in SPEEK matrix. The presence of pores in the microstructure is mainly due to the non-solvent removal and

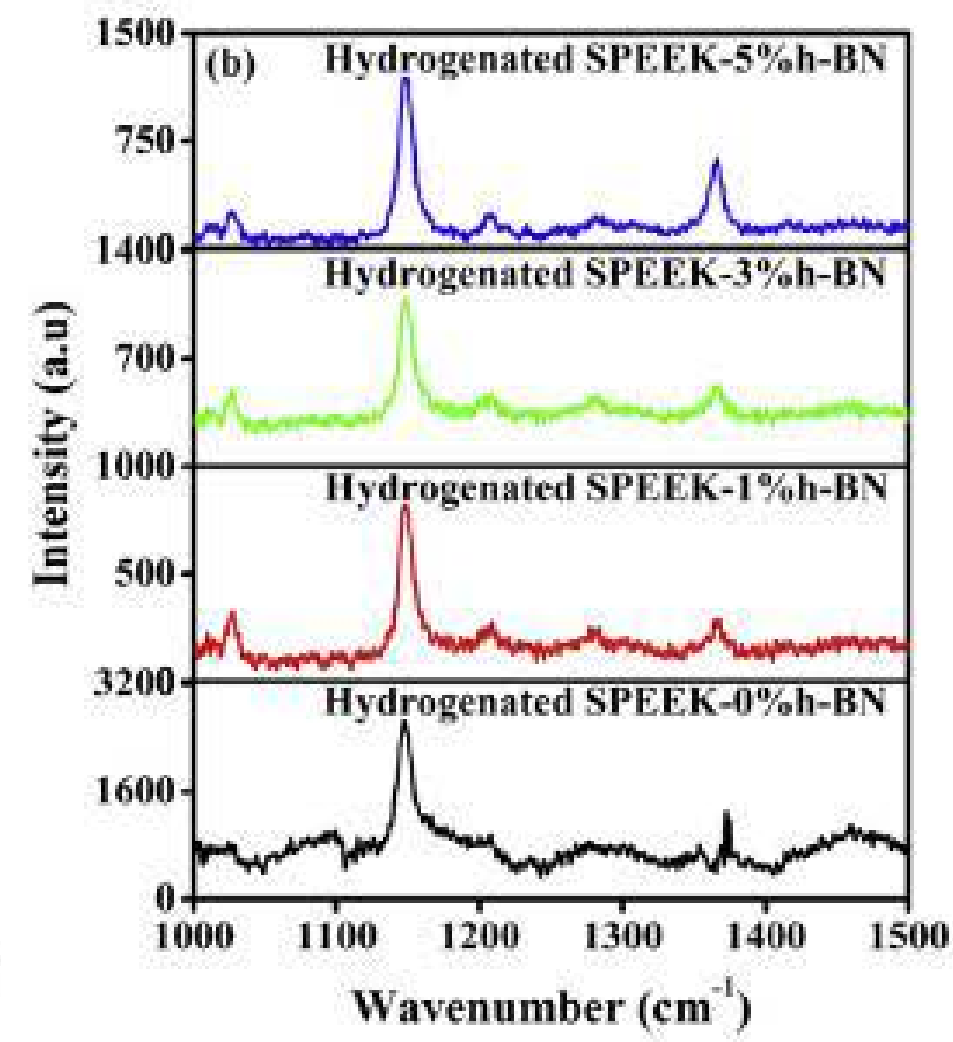

Fig. 8 - (a) XRD spectra (b) Raman spectra of hydrogenated SPEEK-h-BN nanocomposite membranes.

Please cite this article in press as: Naresh Muthu R, et al., Synthesis and characterization of polymer (sulfonated poly-etherether-ketone) based nanocomposite (h-boron nitride) membrane for hydrogen storage, International Joumal of Hydrogen Energy (2014), http://dx.doi.org/10.1016/j.ijhydene.2014.11.136 


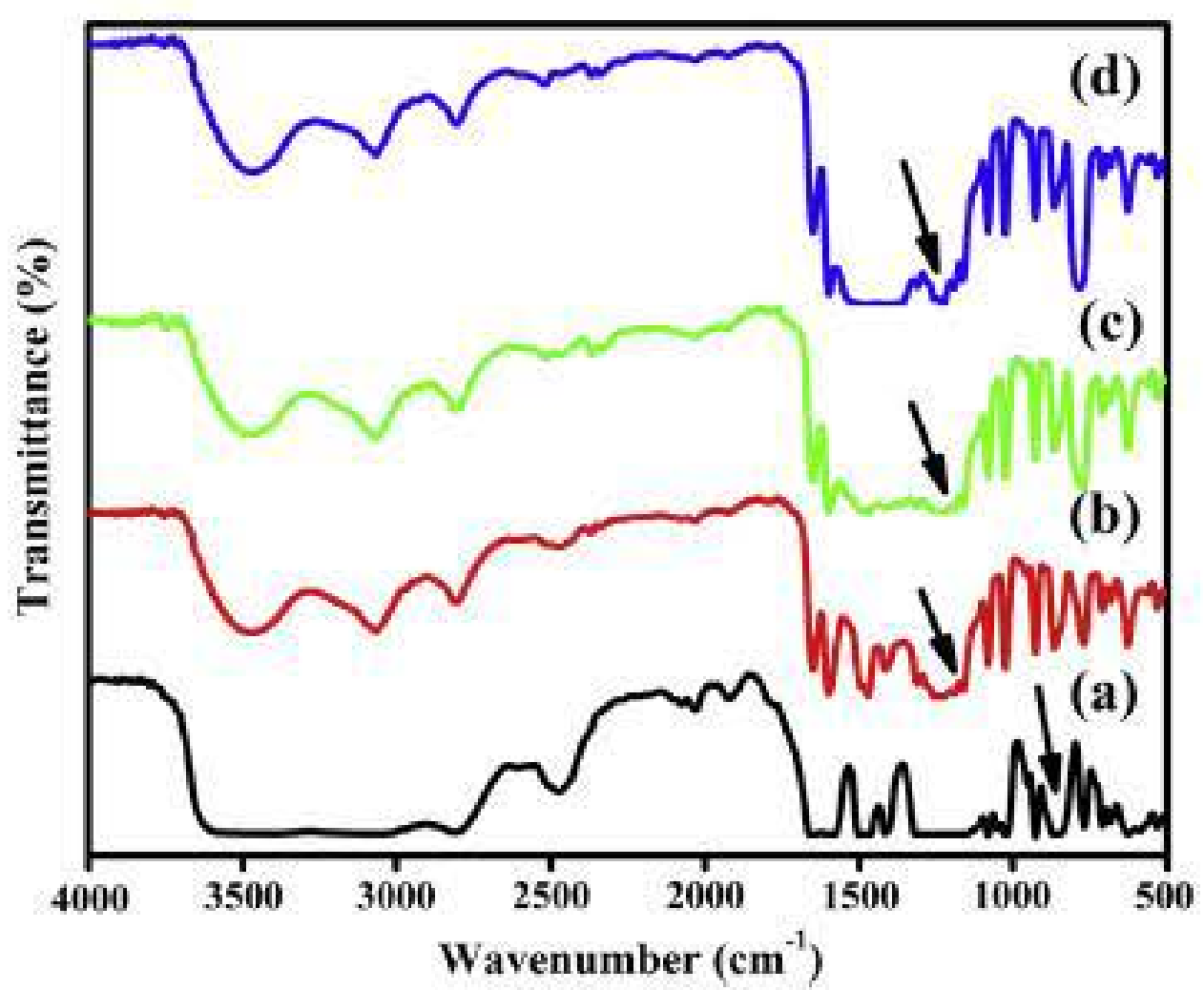

Fig. 9 - FTIR spectra of hydrogenated (a) SPEEK-0\%h-BN (b) SPEEK-1\%h-BN (c) SPEEK-3\%h-BN and (d) SPE्रK-5\%h-BN nanocomposite membranes.

solvent retention ability of the system [56]. Moreover, some of h-BN nanoparticles are distributed uniformly and are highlighted (see Fig. 6b-d).

The topographic images of 2D and 3D of SPEEK-h-BN nanocomposite membranes are captured by AFM and are presented in Fig. 7. From the AFM image, it is evident that the smoothness of membrane surface decreases as the content of $\mathrm{h}$-BN increases in the prepared nanocomposite membranes. Since the phase inversion method has been adopted in the present study, a porous top-layer is formed due to non-solvent removal and creates more pores in the prepared polymer nanocomposite membrane [48]. It is observed that, as the quantity of $\mathrm{h}$-BN increases, the number of pores increases and simultaneously the pore size decreases. Our AFM observations are consistent with the SEM results.

\section{Adsorption analysis}

It is expected that hydrogenated nanocomposite membranes exhibit peculiar behavior. The XRD/Raman spectra (Fig. 8) of hydrogenated SPEEK-h-BN nanocomposites are lower in intensity compared to unhydrogenated membranes and confirm the adsorption of hydrogen. The FTIR spectra of the hydrogenated SPEEK-h-BN nanocomposite membranes are shown in Fig. 9. Due to hydrogenation, some prominent modes are noted that are indicated by arrows in the spectra.

CHN-elemental analysis is performed to find the quantity of hydrogen incorporated in hydrogenated SPEEK-h-BN nanocomposite membranes. The hydrogen storage capacity of the prepared nanocomposite membrane is estimated by finding the difference of hydrogen content in the membranes before and after hydrogenation. The storage capacity of SPEEK-0\%h-BN, SPEEK- $1 \%$ h-BN, SPEEK- $3 \%$ h-BN and SPEEK- $5 \%$ h-BN nanocomposite membranes are found to be $0.66,0.91$, 1.66 and 2.98 wt $\%$, respectively. The presence of more pores in SPEEK matrix and more adsorption sites in the h-BN nanoparticles could be the reason for increased storage capacity in nanocomposite membranes. Therefore, it is concluded that the SPEEK- $5 \%$ h-BN membrane is a more effective hydrogen storage medium than other membranes. The results obtained are compared with earlier reports and are given in Table 2. However, most of the hydrogenation experiments reported in Table 2 have been conducted either at low temperature or at different pressure conditions. Since the present work is conducted at $150^{\circ} \mathrm{C}$, a proper interpretation of our results with earlier works could not be possible. Moreover, the storage of hydrogen at low temperature and high pressure conditions are not realistic for automobile application.

\section{Desorption analysis}

Fig. 10 displays the TG plot of hydrogenated nanocomposite membranes and the inset shows the region where hydrogen desorption takes place. The TGA spectrum of SPEEK-5\%h-BN (see Fig. 10d) exhibits two weight loss, one at the temperature interval of $214-218^{\circ} \mathrm{C}$ and another above $250{ }^{\circ} \mathrm{C}$. The initial weight loss of $2.98 \%$ is attributed to desorption of stored hydrogen in the hydrogenated membrane. The second weight loss starts above $250^{\circ} \mathrm{C}$ which corresponds to the disintegration of SPEEK $[36,39,57]$. Hence, one can confirm that the initial weight loss is due to the release of stored hydrogen and not by the hydrogen in SPEEK. From the desorption temperature, the activation energy of desorption $\left(E_{d}\right)$ was calculated using the following equation $[54,58]$.

$\ln \left(\frac{\mathrm{T}_{\mathrm{m}}^{2}}{\beta}\right)=\frac{\mathrm{E}_{\mathrm{d}}}{\mathrm{RT}_{\mathrm{m}}}$

where, $T_{m}$ is the desorption temperature, $\beta$ is the heating rate $\left(10^{\circ} \mathrm{C} / \mathrm{min}\right)$ and $\mathrm{R}$ is the universal gas constant. Furthermore, the binding energy $\left(E_{B}\right)$ of hydrogen is calculated using the van't Hoff equation $[59,60]$. The calculated values of desorption temperature of hydrogen, activation energy of desorption and binding energy are displayed in Table 1.

In order to make use of these prepared light weight and compact membranes for fuel cell applications, the recommended binding energy of stored hydrogen should be

Table 1 - The desorption parameters in hydrogenated SPत्रत्रK-h-BN nanocomposite.

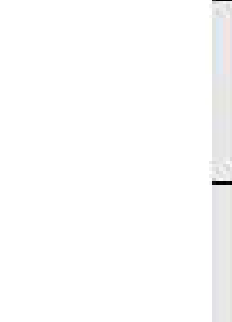$$
\text { ( }
$$

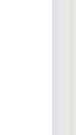$$
\text { Panocomposite }
$$$$
\mathrm{H}_{2}
$$$$
\text { Weight loss }
$$$$
\text { (wt. \%) }
$$

SEE- $0 \%$ - BN

SPEEK- $1 \%$ h-BN

0.66

0.91

1.66

2.98

SPEEK-3\%h-BN

Desorption

temperature range $\left({ }^{\circ} \mathrm{C}\right)$

energy range $(\mathrm{kJ} / \mathrm{mol})$

$190-192$
$201-204$
$204-214$
$214-218$

190-192

204-214

214-218

$25.53-25.67$
$26.32-26.54$
$26.54-27.26$
$27.26-27.56$

25.53-25.67

$26.54-27.26$

27.26-27.56 


\begin{tabular}{|c|c|c|c|}
\hline $\begin{array}{l}\text { Polymer } \\
\text { nanocomposite }\end{array}$ & $\begin{array}{c}\mathrm{H}_{2} \\
\text { (wt \%) }\end{array}$ & Conditions & Reference \\
\hline $\begin{array}{l}\text { Hypercrosslinked } \\
\text { polymers - Pt }\end{array}$ & 0.21 & $298.15 \mathrm{~K}$ and $19 \mathrm{bar}$ & [28] \\
\hline $\begin{array}{l}\text { Hypercrosslinked } \\
\text { Polystyrene - Pt }\end{array}$ & 0.36 & $294 \mathrm{~K}$ and $100 \mathrm{~atm}$ & [29] \\
\hline $\mathrm{PANI}-\mathrm{SnO}_{2}$ & 0.31 & $115^{\circ} \mathrm{C}$ and 70 bar & [30] \\
\hline PANI - MWCNTs & 0.38 & $115^{\circ} \mathrm{C}$ and 70 bar & [30] \\
\hline PANI - Al & 0.5 & $115^{\circ} \mathrm{C}$ and 70 bar & [30] \\
\hline ARP-CTs & 0.62 & $293 \mathrm{~K}$ and $7.5 \mathrm{MPa}$ & [34] \\
\hline HNT - PANI & 0.78 & $\mathrm{RT}$ and $0.5 \mathrm{MPa}$ & [31] \\
\hline PEEK-Manganese oxide & 1.2 & $77 \mathrm{~K}$ & [6] \\
\hline PVA - SWCNTs & 1.2 & $50^{\circ} \mathrm{C}$ & [32] \\
\hline PVP - SWCNTs & 1.5 & $50^{\circ} \mathrm{C}$ & [32] \\
\hline PANI - VONC & 1.8 & $77 \mathrm{~K}$ and $70 \mathrm{bar}$ & [33] \\
\hline SPEEK/h-BN & 2.8 & $150^{\circ} \mathrm{C}$ & $\begin{array}{l}\text { Present } \\
\text { work }\end{array}$ \\
\hline ARP-CTs & 5.2 & $77 \mathrm{~K}$ and $5 \mathrm{MPa}$ & [34] \\
\hline $\begin{array}{l}\text { Li-conjugated } \\
\text { microporous polymers }\end{array}$ & 6 & $77.3 \mathrm{~K}$ and $1 \mathrm{bar}$ & [35] \\
\hline PMMA - Mg & 6 & $250^{\circ} \mathrm{C}$ & [4] \\
\hline
\end{tabular}

$0.2-0.4 \mathrm{eV}[54,58,59,61]$. The obtained binding energy of hydrogenated SPEEK-h-BN nanocomposite membranes lies within this range. Moreover the nanocomposite membranes exhibit $100 \%$ desorption which is estimated by comparing the amount of stored hydrogen from $\mathrm{CHN}$-elemental analysis and desorption of stored hydrogen from TG analysis, where the amount of stored hydrogen is equal to the amount of desorbed hydrogen. Moreover, the hydrogenated SPEEK-h-BN nanocomposite membranes are stable at room temperature. Hence, it is expected that the SPEEK-h-BN nanocomposite membranes could be an effective hydrogen storage medium in near future.

\section{Conclusion}

A lightweight and compact hydrogen storage medium using SPEEK and h-BN was prepared by phase inversion technique. The prepared hydrogen storage medium was subjected to various characterization studies like XRD, micro-Raman, FTIR, SEM, AFM, CHN and TGA. The XRD and micro-Raman results demonstrated the presence of h-BN nanoparticles in SPEEK polymer. The distribution of $\mathrm{h}-\mathrm{BN}$ nanoparticles on the surface of SPEEK was confirmed by SEM and the AFM images indicating the porous nature of membranes. The hydrogenated SPEEK-hBN nanocomposite membranes (hydrogen storage medium) were characterized by XRD, micro-Raman, FTIR, CHN and TGA. The XRD, micro - Raman and FTIR confirm the adsorption of hydrogen in the synthesized SPEEK-h-BN nanocomposite membranes. The hydrogen storage capacity of SPEEK-h-BN nanocomposite membrane increases with increasing h-BN and is due to the larger number of adsorption sites offered by hBN. The hydrogenated membranes are stable at room temperature. A 2.98 wt. \% of hydrogen storage capacity was achieved in SPEEK-5\%h-BN nanocomposite membrane. The average binding energy of hydrogen was found to be $0.38 \mathrm{eV}$ and the nature of hydrogen binding is weak chemisorption. Moreover the desorption temperature was found to be $214-218^{\circ} \mathrm{C}$ for the stored hydrogen to be released and SPEEK-h-
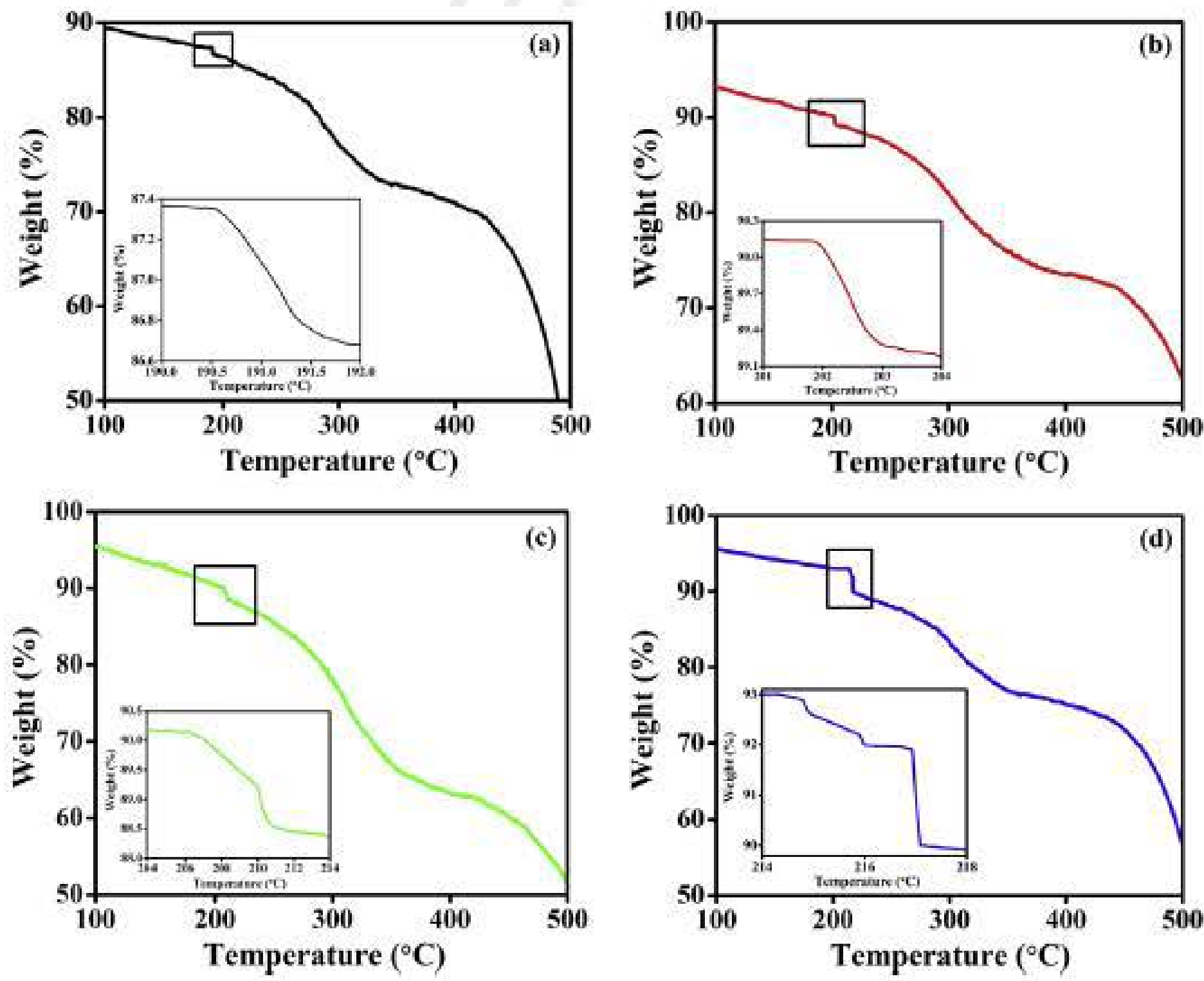

Fig. 10 - TGA spectra of hydrogenated (a) SPEEK-0\%h-BN (b) SPEEK-1\%h-BN (c) SPEEK-3\%h-BN and (d) SPEEK-5\%h-BN nanocomposite membranes.

Please cite this article in press as: Naresh Muthu R, et al., Synthesis and characterization of polymer (sulfonated poly-etherether-ketone) based nanocomposite (h-boron nitride) membrane for hydrogen storage, International Joumal of Hydrogen Energy (2014), http://dx.doi.org/10.1016/j.ijhydene.2014.11.136 
BN membrane shows $100 \%$ desorption. It is clear from the present investigation that the SPEEK-h-BN nanocomposite could be a potential candidate for hydrogen storage in near future for fuel cell application.

\section{Acknowledgments}

One of the authors Dr. S. Rajashabala thanks University Grants Commission of India for providing grant to carry out this work under UGC-MRP. The authors acknowledge UGCUPE for micro-Raman, DST-FIST for XRD, DST-PURSE for AFM studies and USIC-MKU for FTIR characterizations.

\section{RE F E R E N C E S}

[1] Abraham S. National hydrogen energy roadmap (Based on the results of the national hydrogen energy roadmap workshop, Washington, DC). April 2-3, 2002.

[2] Nejad SE, Shokuhfar A. Compressive buckling of open-ended boron nitride nanotubes in hydrogen storage applications. Phys E 2013;50:29-36.

[3] Hou P-X, Yang Q-H, Bai S, Xu S-T, Liu M, Cheng H-M. Bulk storage capacity of hydrogen in purified multiwalled carbon nanotubes. J Phys Chem B 2002;106:963-6.

[4] Makridis SS, Gkanas EI, Panagakos G, Kikkinides ES, Stubos AK, Wagener P, et al. Polymer-stable magnesium nanocomposites prepared by laser ablation for efficient hydrogen storage. Int J Hydrogen Energy 2013;38:11530-5.

[5] Zhang Z-W, Zheng W-T, Jiang Q. Hydrogen adsorption on Ce/ BNNT systems: a DFT study. Int J Hydrogen Energy 2012;37:5090-9.

[6] Pedicini R, Sacca A, Carbone A, Passalacqua E. Hydrogen storage based on polymeric material. Int J Hydrogen Energy 2011;36:9062-8.

[7] Silambarasan D, Vasu V, lyakutti K, Surya VJ, Ravindran TR. Reversible hydrogen storage in functionalized single-walled carbon nanotubes. Phys E 2014;60:75-9.

[8] Sanyal U, Demirci UB, Jagirdar BR, Miele P. Hydrolysis of ammonia borane as a hydrogen source: fundamental issues and potential solutions towards implementation. Chem Sus Chem 2011;4:1731-9.

[9] Azzouz A. Achievement in hydrogen storage on adsorbents with high surface-to-bulk ratio e prospects for Si-containing matrices. Int J Hydrogen Energy 2012;37:5032-49.

[10] Gutowska A, Li L, Shin Y, Wang CM, Li XS, Linehan JC, et al. Nanoscaffold mediates hydrogen release and the reactivity of ammonia borane. Angew Chem Int Ed $2005 ; 44: 3578-82$.

[11] Ichikawa T, Isobe S, Hanada N, Fujii H. Lithium nitride for reversible hydrogen storage. J Alloys Compd 2004;365:271-6.

[12] Nouar F, Eckert J, Eubank JF, Forster P, Eddaoudi M. Zeolitelike metal-organic frameworks (ZMOFs) as hydrogen storage platform: lithium and magnesium ion-exchange and $\mathrm{H}_{2}$ (rho-ZMOF) interaction studies. J Am Chem Soc 2009;131:2864-70.

[13] Satyapal S, Petrovic J, Reada C, Thomas G, Ordaz G. The U.S. department of energy's national hydrogen storage project: progress towards meeting hydrogen-powered vehicle requirements. Catal Today 2007;120:246-56.

[14] Bénard P, Chahine R. Storage of hydrogen by physisorption on carbon and nanostructured materials. Scr Mater 2007;56:803-8.
[15] Kosa M, Krack M, Cheetham AK, Parrinello M. Modeling the hydrogen storage materials with exposed $\mathrm{M}^{2+}$ coordination sites. J Phys Chem C 2008;112(42):16171-3.

[16] Stergiannakos T, Tylianakis E, Klontzas E, Froudakis GE. Enhancement of hydrogen adsorption in metal-organic frameworks by $\mathrm{Mg}^{2+}$ functionalization: a multiscale computational study. J Phys Chem C 2010;114:16855-8.

[17] Yang Z, Xia Y, Mokaya R. Enhanced hydrogen storage capacity of high surface area zeolite-like carbon materials. J Am Chem Soc 2007;129:1673-9.

[18] Weng Q Wang X, Zhi C, Bando Y, Golberg D. Boron nitride porous microbelts for hydrogen storage. ACS Nano 2013;7(2):1558-65.

[19] Wang P, Orimo S, Matsushima T, Fujii H. Hydrogen in mechanically prepared nanostructured h-BN: a critical comparison with that in nanostructured graphite. Appl Phys Lett 2002;80:318-20.

[20] Ma R, Bando Y, Zhu H, Sato T, Xu C, Wu D. Hydrogen uptake in boron nitride nanotubes at room temperature. J Am Chem Soc 2002;124(2):7672-3.

[21] Tang C, Bando Y, Ding X, Qi S, Golberg D. Catalyzed collapse and enhanced hydrogen storage of BN nanotubes. J Am Chem Soc 2002;124:14550-1.

[22] Li J, Lin J, Xu X, Zhang X, Xue Y, Mi J, et al. Porous boron nitride with a high surface area: hydrogen storage and water treatment. Nanotechnology 2013;24:155603 (7pp).

[23] Kim KK, Hsu A, Jia X, Kim SM, Shi Y, Hofmann M, et al. Synthesis of monolayer hexagonal boron nitride on cu foil using chemical vapor deposition. Nano Lett 2012;12:161-6.

[24] Kho J-G, Moon K-T, Kim J-H, Kim D-P. Properties of Boron nitride $\left(\mathrm{B}_{\mathrm{x}} \mathrm{N}_{\mathrm{y}}\right)$ films produced by the spin-coating process of polyborazine. J Am Ceram Soc 2000;83(11):2681-3.

[25] Keown NBM, Gahnem B, Msayib KJ, Budd PM, Tattershall CE, Mahmood K, et al. Towards polymer-based hydrogen storage materials : engineering ultramicroporous cavities within polymers of intrinsic microporosity. Angew Chem Int Ed 2006;45:1804-7.

[26] Lee J-Y, Wood CD, Bradshaw D, Rosseinsky M], Cooper AI. Hydrogen adsorption in microporous hypercrosslinked polymers. Chem Commun 2006:2670-2.

[27] Cho SJ, Choo K, Kim DP, Kim JW. $\mathrm{H}_{2}$ sorption in $\mathrm{HCl}$ treated polyaniline and polypirrole. Catal Today 2007;120:336-40.

[28] Li B, Huang X, Gong R, Ma M, Yang X, Liang L, et al. Catalyzed hydrogen spillover for hydrogen storage on microporous organic polymers. Int J Hydrogen Energy 2012;37:12813-20.

[29] Demirocak DE, Ram MK, Srinivasan SS, Kumar A, Goswami DY, Stefanakos EK. Spillover enhancement for hydrogen storage by Pt doped hypercrosslinked polystyrene. Int J Hydrogen Energy 2012;37:12402-10.

[30] Jurczyka MU, Kumar A, Srinivasan S, Stefanakos E. Polyaniline-based nanocomposite materials for hydrogen storage. Int J Hydrogen Energy 2007;32:1010-5.

[31] Attia NF, Menemparabath MM, Arepalli S, Geckeler KE. Inorganic nanotube composites based on polyaniline: potential room-temperature hydrogen storage materials. Int J Hydrogen Energy 2013;38:9251-62.

[32] Silambarasan $D$, Vasu V, lyakutti $K$. Water soluble polymerSWCNT-based composite for hydrogen storage. IEEE Trans Nanotechnology 2014;13(2):261-7.

[33] Kim BH, Hong WG, Lee SM, Yun YJ, Yu HY, Oh S-Y, et al. Enhancement of hydrogen storage capacity in polyaniline vanadium pentoxide nanocomposites. Int J Hydrogen Energy 2010;35:1300-4.

[34] Chen Y, Zhu H, Liu Y. Preparation of activated rectangular polyaniline-based carbon tubes and their application in hydrogen adsorption. Int J Hydrogen Energy 2011;36:11738-45. 
[35] Li A, Lu R-F, Wang Y, Wang X, Han K-L, Deng W-Q. Lithiumdoped conjugated microporous polymers for reversible hydrogen storage. Angew Chem Int Ed 2010;49:3330-3.

[36] Gupta D, Choudhary V. Studies on novel heat treated sulfonated poly(ether ether ketone) [SPEEK]/diol membranes for fuel cell applications. Int J Hydrogen Energy 2011;36:8525-35.

[37] Lau W], Ismail AF. Theoretical studies on the morphological and electrical properties of blended PES/SPEEK nanofiltration membranes using different sulfonation degree of SPEEK. J Membr Sci 2009;334:30-42.

[38] Lim SS, Daud WRW, Jahim JM, Ghasemi M, Chong PS, Ismail M. Sulfonated poly(ether ether ketone)/poly(ether sulfone) composite membranes as an alternative proton exchange membrane in microbial fuel cells. Int J Hydrogen Energy 2012;37:11409-24.

[39] Zaidi SM], Mikhailenko SD, Robertson GP, Guiver MD, Kaliaguine S. Proton conducting composite membr anes from polyether ether ketone and heteropolyacids for fuel cell applications. J Membr Sci 2000;173:17-34.

[40] Young T-H, Chen L-W. Pore formation mechanism of membranes from phase inversion process. Desalination 1995;103:233-47.

[41] Xi J, Qiu X, Li J, Tang X, Zhu W, Chen L. PVDF-PEO blends based microporous polymer electrolyte: effect of PEO on pore configurations and ionic conductivity. J Power Sources 2006;157:501-6.

[42] Wu H-L, Ma C-CM, Li C-H, Lee T-M, Chen C-Y, Chiang C-L, et al. Sulfonated poly(ether ether ketone)/poly(amide imide) polymer blends for proton conducting membrane. J Membr Sci 2006;280:501-8.

[43] Handayani S, Dewi EL. Influence of silica/sulfonated polyether-ether ketone as polymer electrolyte membrane for hydrogen fueled proton exchange membrane fuel cells. Internat J Sci Eng 2011;2(2):26-30.

[44] Terao T, Bando Y, Mitome M, Zhi C, Tang C, Golberg D. Thermal conductivity improvement of polymer films by catechin-modified boron nitride nanotubes. J Phys Chem C 2009;113:13605-9.

[45] Cakmakc E, Kocyigit C, Cakur S, Durmus A, Kahraman MV. Preparation and characterization of thermally conductive thermoplastic polyurethane/h-BN nanocomposites. Polym Compos 2014:530-8.

[46] Zhi C, Bando Y, Tang C, Honda S, Sato K, Kuwahara H, et al. Characteristics of boron nitride nanotube - polyaniline composites. Angew Chem in Ed Engl 2005;44:7929-32.

[47] Ramalingam S, Periandy S, Sugunakala S, Prabhu T, Bououdina M. Insilico molecular modeling, docking and spectroscopic [FT-IR/FT-Raman/UV/NMR] analysis of chlorfenson using computational calculations. Spectrochim Acta Part 2013;115:118-35.

[48] Reddy ALM, Tanur AE, Walker GC. Synthesis and hydrogen storage properties of different types of boron nitride nanostructures. Int J Hydrogen Energy 2010;35:4138-43.
[49] Chen C-Y, Cheng C-T, Lai C-W, Wu P-W, Wu K-C, Chou P-T, et al. Potassium ion recognition by 15 -crown- 5 functionalized $\mathrm{CdSe} / \mathrm{ZnS}$ quantum dots in $\mathrm{H}_{2} \mathrm{O}$. Chem Commun 2006:263-5.

[50] Deivanayagam P, Ramamoorthy AR. Sulfonated poly(ether ether ketone) and poly(ethylene glycol) diacrylate based semi-interpenetrating network membranes for fuel cells. J Macromol Sci Pure Appl Chem 2012;49:191-200.

[51] Xing P, Robertson GP, Guiver MD, Mikhailenko SD, Wang K, Kaliaguine S. Synthesis and characterization of sulfonated poly(ether ether ketone) for proton exchange membranes. J Membr Sci 2004;229:95-106.

[52] Wu H-L, Ma C-CM, Kuan H-C, Wang C-H, Chen C-Y, Chiang C-L. Sulfonated poly(ether ether ketone)/ poly(vinylpyrrolidone) acid-base polymer blends for direct methanol fuel cell application. J Polym Sci Part B Polym Phys 2006;44:565-72.

[53] Li W, Fu YZ, Manthiram A, Guiver MD. Blend membranes consisting of sulfonated poly(ether ether ketone) and polysulfone bearing 4-nitrobenzimidazole for direct methanol fuel cells. J Electrochem Soc 2009;156(2):B258-63.

[54] Silambarasan D, Vasu V, Surya V], Iyakutti K. Investigation of hydrogen desorption from hydrogenated single-walled carbon nanotubes functionalized with borane. IEEE Trans Nanotechnol 2012;11(5):1047-53.

[55] Silambarasan D, Surya VJ, Vasu V, lyakutti K. Experimental investigation of hydrogen storage in single walled carbon nanotubes functionalized with borane. Int J Hydrogen Energy 2011;36:3574-9.

[56] Kazmiruk V. Scanning electron microscopy. surface analysis studies on polymer electrolyte membranes using scanning electron microscope and atomic force microscope [chapter 33]. InTech; 2012.

[57] Gupta D, Madhukar A, Choudhary V. Effect of functionality of polyhedral oligomericsilsesquioxane [POSS] on the properties of sulfonated poly(ether ether ketone) [SPEEK] based hybrid nanocomposite proton exchange membranes for fuel cell applications. Int J Hydrogen Energy 2013;38:12817-29.

[58] Silambarasan D, Surya V], Vasu V, lyakutti K. Single walled carbon nanotube-metal oxide nanocomposites for reversible and reproducible storage of hydrogen. ACS Appl Mater Interfaces 2013;5:11419-26.

[59] Jhi S-H. Activated boron nitride nanotubes: a potential material for room-temperature hydrogen storage. Phys Rev B 2006;74:155424.

[60] Jhi S-H, Kwon Y-K. Glassy materials as a hydrogen storage medium: density functional calculations. Phys Rev B 2005;71:035408.

[61] Lochan RC, Gordon MH. Computational studies of molecular hydrogen binding affinities: the role of dispersion forces, electrostatics, and orbital interactions. Phys Chem Chem Phys 2006;8:1357-70. 